\title{
Development of a Coupled Enzyme Assay Method for Microsomal Prostaglandin E Synthase Activity
}

\author{
Kyung-A Choi, Sung-Jun Park, and Yeon Gyu Yu* \\ Department of Chemistry, Kookmin University, Seoul 136-702 Korea. *E-mail: ygyu@kookmin.ac.kr \\ Received December 14, 2009, Accepted December 30, 2009
}

\begin{abstract}
Human microsomal prostaglandin E synthase-1 (mPGES-1) catalyzes the conversion of prostaglandin $\mathrm{H}_{2}\left(\mathrm{PGH}_{2}\right)$ into prostaglandin $\mathrm{E}_{2}\left(\mathrm{PGE}_{2}\right)$. To establish a stable and efficient method to assess the activity of mPGES-1, a coupled enzyme assay system using mPGES-1, 15-hydroxyprostaglandin dehydrogenase (15-PGDH) and phosphomolybdic acid (PMA) was developed. In this assay system, $\mathrm{PGH}_{2}$ was converted to $\mathrm{PGE}_{2}$ by $\mathrm{mPGES}-1$, and then $\mathrm{PGE}_{2} \mathrm{Was}_{\text {further trans- }}$ formed to the 15-keto- $\mathrm{PGE}_{2}$ by 15-PGDH accompanying the production of NADH, which was easily detected by fluorescence spectrometry in a multi-well plate format. During the reaction, spontaneous oxidation of $\mathrm{PGH}_{2}$ was prevented by PMA. Using this novel assay, the $\mathrm{K}_{\mathrm{m}}$ value of mPGES- 1 for $\mathrm{PGH}_{2}$ and the $\mathrm{IC}_{50}$ value of the previously characterized inhibitor, MK-886, were determined to be $0.150 \mathrm{mM}$ and $2.8 \mu \mathrm{M}$, respectively, which were consistent with the previously reported values. In addition, low backgrounds were observed in the multi-wall plate screening of chemical compounds.
\end{abstract}

Key Words: mPGES-1, 15-PGDH, Fluorescence, NADH, Coupled enzyme assay

\section{Introduction}

Prostaglandins derived from arachidonic acid have been implicated in various physiological processes. ${ }^{1}$ Particularly, prostaglandin $\mathrm{E}_{2}\left(\mathrm{PGE}_{2}\right)$ is involved in inflammation, ${ }^{2-4}$ reproduction, ${ }^{5}$ or tumorigenesis. ${ }^{6,7} \mathrm{PGE}_{2}$ is produced in macrophages and other tissues by inflammatory stimuli ${ }^{8-11}$ and mediates fever and pain. ${ }^{12,13}$ Hence, the biosynthetic pathway of $\mathrm{PGE}_{2}$ has been a primary target in the development of anti-inflammatory agents. In human, a cytosolic prostaglandin $\mathrm{E}_{2}$ synthase (cPGES), ${ }^{14}$ and two microsomal membrane-associated prostaglandin $\mathrm{E}_{2}$ synthases (mPGES-1 and mPGES-2) ) $^{2,3}$ have been identified. Among them, mPGES-1 was responsible for the acute increase of $\mathrm{PGE}_{2}$ induced by proinflammatory stimuli in various tissues. ${ }^{3,4,7}$ The knockout of mPGES-1 gene in mouse showed impaired inflammatory and pain responses, ${ }^{15}$ indicating that a potent inhibitor of mPGES-1 may be a promising drug for the treatment of chronic inflammatory diseases such as rheumatism. ${ }^{16}$

Human mPGES-1 cleaves the alkylperoxide bond of prostaglandin $\mathrm{H}_{2}\left(\mathrm{PGH}_{2}\right)$, and forms a hydroxide and ketone group. Since the substrate $\left(\mathrm{PGH}_{2}\right)$ and product $\left(\mathrm{PGE}_{2}\right)$ of mPGES-1 have no distinguishable chromophores, the activity of mPGES-1 cannot be assayed by a spectroscopic method that measures the amount of $\mathrm{PGE}_{2}$. Instead, the amount of $\mathrm{PGE}_{2}$ could be measured by anti-PGE 2 antibody. ${ }^{17}$ Alternatively, the $\mathrm{PGE}_{2}$ has been separated by HPLC after the reaction, and its relative amount was directly measured from the elution profile of the reaction products. ${ }^{8,18,19}$ A spectrometric method to assay mPGES-1 was previously developed. $^{20}$ This method consisted of mPGES-1, COX-2, 15-hydroxyprostaglandin dehydrogenase (PGDH), arachidonic acid and $\mathrm{NAD}^{+}$. In this assay system, $\mathrm{PGH}_{2}$ was synthesized by COX-2, and then further converted to $\mathrm{PGE}_{2}$ and 15keto-PGE ${ }_{2}$ by mPGES-1 and 15-PGDH, respectively. The amount of NADH produced by $15-\mathrm{PGDH}$ during $\mathrm{NAD}^{+}$-dependent oxidation of the 15-hydroxy group of $\mathrm{PGE}_{2}$ was measured by absorption at $340 \mathrm{~nm}$ or its fluorescence intensity at an excitation and emission wavelength of $340 \mathrm{~nm}$ and $468 \mathrm{~nm}$, respectively.

All of the reported assay methods for assessing mPGES-1 activity can only screen simultaneously a small number of chemicals due to the unstable nature of $\mathrm{PGH}_{2}$. The peroxide bond of $\mathrm{PGH}_{2}$ is spontaneously cleaved to form $\mathrm{PGE}_{2}, \mathrm{PFD}_{2}$ or $\mathrm{PGF}_{2 \alpha}$ in solution with a half life of less than $10 \mathrm{~min}$ at $20^{\circ} \mathrm{C}^{21-23}$ These products from the spontaneous decomposition of $\mathrm{PGH}_{2}$ generated high background signal in these assay systems since they could be further oxidized by 15-PGDH accompanying the reduction of NAD ${ }^{+}$. Thus, this property of $\mathrm{PGH}_{2}$ has limited the reaction time to less than a minute in all the reported assay methods. ${ }^{22}$ Hence, the stabilization of $\mathrm{PGH}_{2}$ or the prevention of spontaneous cleavage of the peroxide bond in $\mathrm{PGH}_{2}$ would enhance the application of the mPGES-1 assay methods for the screening of inhibitors from a large number of chemical compounds.

In this study, we developed a novel coupled enzyme assay method that consists of purified recombinant mPGES-1 and 15PGDH. The activity of mPGES-1 was efficiently assayed by measuring the amount of NADH converted from $\mathrm{NAD}^{+}$by $15-$ PGDH using a fluorescence plate reader. In particular, $\mathrm{PGH}_{2}$ was stabilized by $0.1 \mathrm{mM}$ phosphomolybdic acid (PMA) and the spontaneous decomposition of $\mathrm{PGH}_{2}$ to $\mathrm{PGF}_{2 \alpha}$ was effectively prevented during the reaction period. This method provides a robust assay system that can be applied for screening large chemical libraries.

\section{Materials and Methods}

Materials. Prostaglandin $\mathrm{H}_{2}\left(\mathrm{PGH}_{2}\right)$, phosphomolybdic acid (PMA) and MK-886 was obtained from Sigma (USA). A 96well black non-binding plate, which was used in the mPGES-1 assay, was obtained from Cayman Chemical Company (USA). Glutathione (GSH), nicotinamide adenine dinucleotide $\left(\mathrm{NAD}^{+}\right)$, and dithiothreitol (DTT) were purchased from USB Corp. 
(USA), Sigma (USA) and Bio Basic Inc. (Canada), respectively.

Preparation of mPGES-1 and 15-PGDH. The coding region of human mPGES-1 containing a His 6 -tag at the N-terminus was expressed in E. coli Rosetta(DE3) and purified as previously described. ${ }^{24}$ Briefly, the expression of recombinant mPGES-1 was induced with $1 \mathrm{mM}$ IPTG for $12 \mathrm{hr}$ at $18^{\circ} \mathrm{C}$, and the recovered cells were lysed by ultrasonication. After the remaining cell debris in the lysate was removed by centrifugation at $5,000 \times \mathrm{g}$ for $10 \mathrm{~min}$ at $4^{\circ} \mathrm{C}$, and the membrane fraction was precipitated by ultracentrifugation at $100,000 \times \mathrm{g}$ for $1 \mathrm{hr}$ at $4{ }^{\circ} \mathrm{C}$. The membrane fraction was solubilized with $20 \mathrm{~mL}$ of buffer A (15 mM Tris- $\mathrm{HCl}, \mathrm{pH} 7.4,150 \mathrm{mM} \mathrm{NaCl}, 10 \%$ glycerol, 0.5 mM EDTA, 1 mM PMSF, $1 \mathrm{mM} \mathrm{GSH}$, and 4\% Triton X-100). The solubilized mPGES-1 was further purified by a Ni-NTA and mono-Q column, successively. ${ }^{24}$ For the preparation of $15-$ PGDH, an expression vector of 15-PGDH was prepared by inserting the coding sequence of human15-PGDH (gi: 3248) in p15PGDH (kindly provided from Prof. Cho Hoon at Chosun Univ., Korea) into the BamHI and EcoRI sites of pGEX-2T vector. The GST-tag labeled 15-PGDH was expressed in E. coli Rosetta(DE3), and purified as previously described. ${ }^{25}$ Briefly, the expression of recombinant 15-PGDH was induced with $1 \mathrm{mM}$ IPTG for $12 \mathrm{hr}$ at $25^{\circ} \mathrm{C}$, and the recovered cells were lysed using a microfluidizer. After the remaining cell debris in the lysate was removed by centrifugation at $10,000 \times \mathrm{g}$ for $20 \mathrm{~min}$ at $4{ }^{\circ} \mathrm{C}$, the lysate was loaded onto GSH-agarose column and the bound 15-PGDH was eluted with $10 \mathrm{mM}$ reduced glutathione in $50 \mathrm{mM}$ Tris-HCl, $1 \mathrm{mM}$ EDTA, $0.1 \mathrm{mM}$ DTT and $\mathrm{pH}$ 8.0.

Enzyme assay. To measure the activity of mPGES-1, 0.72 $\mu \mathrm{g}$ of mPGES-1 and $1.1 \mu \mathrm{g}$ of 15-PGDH were mixed in $200 \mu \mathrm{L}$ of the reaction buffer ( $50 \mathrm{mM}$ Tris- $\mathrm{HCl}, 0.1 \mathrm{mM}$ of PMA, $2 \mathrm{mM}$ reduced form of glutathione, $2 \mathrm{mM} \mathrm{NAD}^{+}, 0.1 \mathrm{mM}$ DTT, $\mathrm{pH}$ 7.5). The reaction was initiated by adding cold $\mathrm{PGH}_{2}$ to a final concentration of $6 \mu \mathrm{M}$. The amount of NADH in the reaction product was measured by fluorescence reader (DYNEX, USA) using an emission and excitation wavelength of $468 \mathrm{~nm}$ and $340 \mathrm{~nm}$, respectively using a plate reader (DYNEX, USA). The inhibitory activity of chemical compounds was measured by incubating $20 \mu \mathrm{M}$ of the compounds $1 \mu \mathrm{L}$ in dimethylsolfoxide (DMSO) with mPGES-1 for 30 min prior to the addition of $\mathrm{PGH}_{2}$. The amount of $\mathrm{PGE}_{2}$ was measured using anti-PGE $\mathrm{PG}_{2}$ antibody and $\mathrm{PGE}_{2}$-conjugated alkaline phosphatase ${ }^{17}$ as described in the instruction manual (Assay Designs, Inc., USA). The protein concentration was measured by the Lowry method using bovine serum albumin as a standard. ${ }^{26}$

\section{Results and Discussion}

Preparation mPGES-1 and 15-PGDH. We used pET28a and pGEX-2T expression vectors to express mPGES-1 and 15-PG$\mathrm{DH}$, respectively. The coding sequence of human mPGES-1 containing a N-terminus His $_{6}$-tag was cloned in pET28a, and the recombinant protein expressed in E. coli Rossetta (DE3) was purified from the crude extract by a NTA-column and mono-Q column, as described previously ${ }^{24}$ (Fig. 1A). The coding region of human 15-PGDH was cloned into the pGEX-2T expression vector, which expressed a fusion protein of 15-PGDH linked at the $\mathrm{C}$-terminus to glutathione $\mathrm{S}$-transferase. The recombinant protein was purified from the crude extract by a single step of GSH-agarose column (Fig. 1B). Both mPGES-1 and 15-PDGH were purified to more than $90 \%$ purity, and their molecular weights were estimated to be 17 and $52 \mathrm{kDa}$, respectively.

Optimization of coupled enzyme assay by PMA-dependent stabilization of $\mathbf{P G H}_{2}$. To establish the coupled enzyme assay, the fluorescence intensity of NADH was measured at $468 \mathrm{~nm}$ under various conditions. The specific activity of mPGES-1 $(120 \mu \mathrm{mol} / \mathrm{min} / \mathrm{mg})^{24,27}$ was 6-fold lower than that of 15-PGDH $(830 \mu \mathrm{mol} / \mathrm{min} / \mathrm{mg}) .{ }^{28}$ In the reaction mixture, about 10 -fold higher specific activity of 15-PGDH $(1.1 \mu \mathrm{g})$ than that of $\mathrm{mP}-$ GES-1 $(0.72 \mu \mathrm{g})$ was used to efficiently measure the activity of mPGES-1. As shown in Fig. 2A, NADH was produced right after the addition of $\mathrm{PGH}_{2}$ to the reaction mixture and reached to constant level after $20 \mathrm{~min}$ or longer incubation (Fig. 2A, $\mathbf{\Delta}$ ), indicating most of $\mathrm{PGH}_{2}$ was consumed within $20 \mathrm{~min}$. In comparison, a significant amount of NADH was also produced from

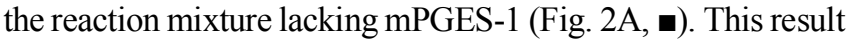
indicates that more than $70 \%$ of $\mathrm{PGH}_{2}$ was decomposed in the absence of mPGES- 1 and used as substrates of PGDH. To prevent the spontaneous decomposition of $\mathrm{PGH}_{2}$, the production of NADH from the reaction mixture containing 15-PGDH, NAD ${ }^{+}$ and $\mathrm{PGH}_{2}$ was measured in the presence of $0.1 \mathrm{mM} \mathrm{PMA}$, which had been identified as stabilizers of peroxidicarbonates. ${ }^{29}$ As shown in Fig. 2B, the amount of NADH generated from the reaction mixture containing only 15-PGDH was undetectable (Fig. $2 \mathrm{~B}, \boldsymbol{\square})$. Whereas, significant amount of NADH was produced after the addition of $\mathrm{PGH}_{2}$ in the reaction mixture containing both mPGES-1 and 15-PGDH (Fig. 2B, $\mathbf{\Delta}$ ), and saturated after $10 \mathrm{~min}$. The fluorescence intensity from the reaction mixture
(A)

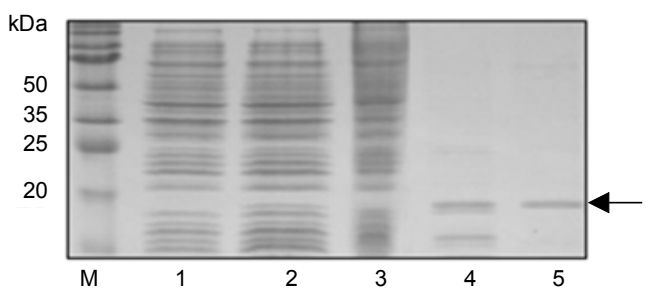

(B)

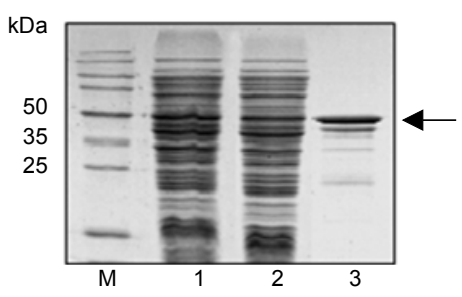

Figure 1. SDS-PAGE analysis of the purified recombinant mPGES-1 (A) and 15-PGDH (B). (A) The recombinant mPGES-1 samples were analyzed by $15 \%$ SDS-PAGE. Lane M, molecular weight markers; lane 1, crude extract before IPTG-induction, lane 2, after IPTG-induction; lane 3, membrane fraction; lane 4, after NTA-column; lane 5, and after Q-sepharose column. (B) The recombinant 15-PGDH samples were analyzed by $12 \%$ SDS-PAGE. Lane M, molecular weight markers; lane 1, crude extract after IPTG-induction; lane 2. unbound proteins from glutathione column; lane 3 after glutathione column. The purified mPGES-1 and 15-PGDH were indicated as arrows. 

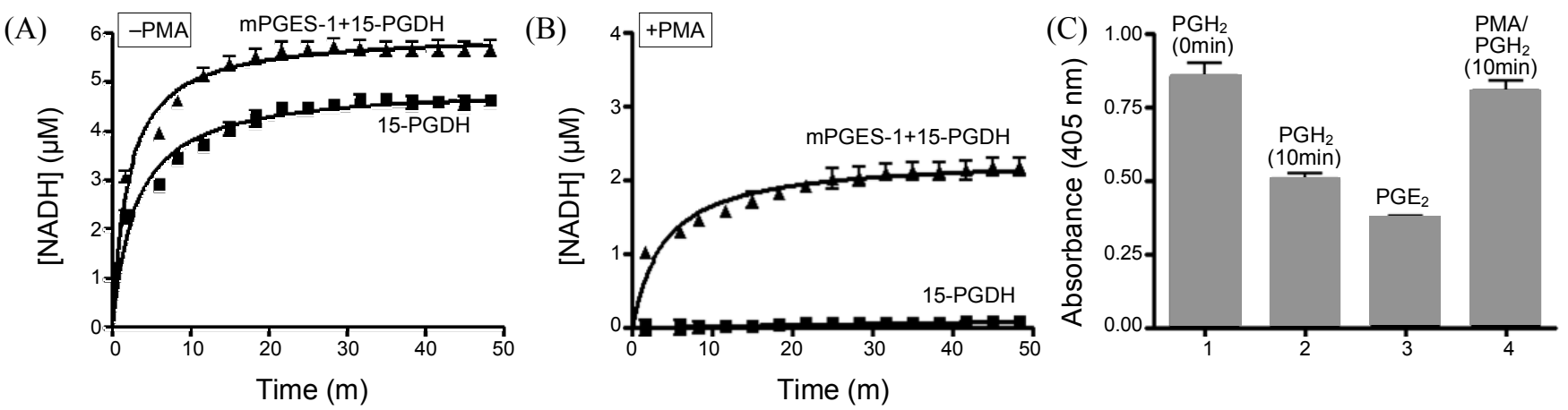

Figure 2. PMA prevents the spontaneous decomposition of $\mathrm{PGH}_{2}$. (A) The fluorescence intensity of NADH from the reaction mixture containing $\mathrm{NAD}^{+}, \mathrm{mPGES}-1$ and $15-\mathrm{PGDH}$ was measured over $30 \mathrm{~min}$ after the addition of $\mathrm{PGH}_{2}$ at room temperature $(\mathbf{\Lambda})$. Likewise, the fluorescence intensity from the same reaction mixture except lacking mPGES-1 was also measured ( $\mathbf{a})$. (B) The fluorescence intensity of NADH from the reaction mixture

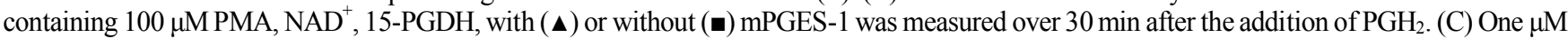
of fresh $\mathrm{PGH}_{2}$ (bar 1), $\mathrm{PGH}_{2}$ after incubation for 10 min at room temperature (bar 2), $\mathrm{PGE}_{2}$ (bar 3), or $\mathrm{PGH}_{2}$ after incubation for 10 min at room temperature with $0.1 \mathrm{mM}$ PMA (bar 4) was incubated in 96-well plate coated with anti-PGE 2 antibody for 10 min at $4{ }^{\circ} \mathrm{C}$, and the amount of $\mathrm{PGE}_{2}$ - labeled alkaline phosphatase bound to the plate was measured.

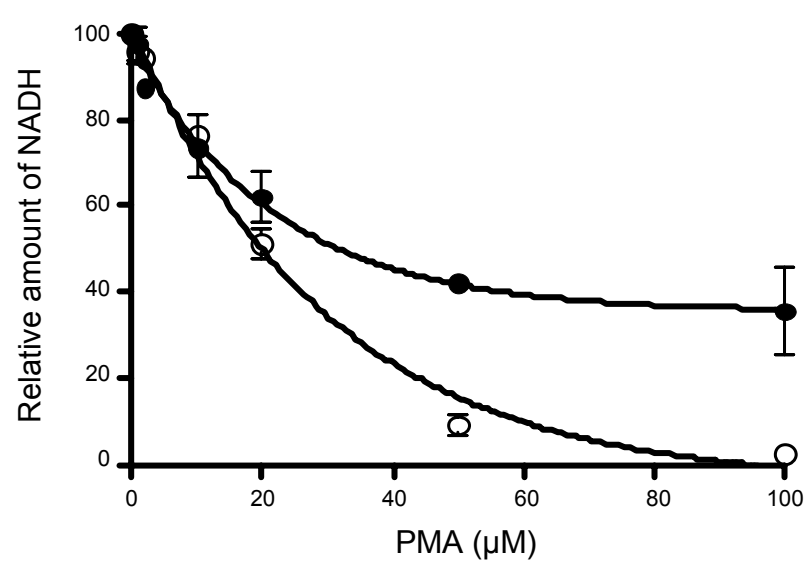

Figure 3. Concentration dependent stabilization of $\mathrm{PGH}_{2}$ by PMA. The effect of $\mathrm{PMA}$ on the stabilization of $\mathrm{PGH}_{2}$ was examined by measuring the amount of NADH produced from the reaction mixture containing both mPGES-1 and 15-PGDH $(\bullet)$ or the mixture containing only $15-$ PGDH (०) and different concentrations of PMA after incubation at room temperature for $20 \mathrm{~min}$.

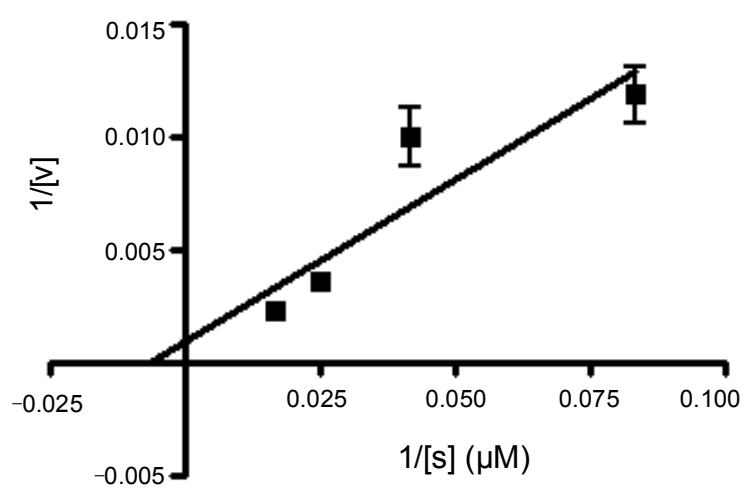

Figure 4. Lineweaver-Burk plot of the coupled-enzyme assay. The initial velocity of the reaction containing $0.2 \mu \mathrm{M}$ mPGES-1, $1.0 \mu \mathrm{M} 15-$ $\mathrm{PDGH}$, and $100 \mu \mathrm{M}$ PMA was measured within $40 \mathrm{sec}$ at different concentrations of $\mathrm{PGH}_{2}$, and the $1 /[\mathrm{v}]$ values were plotted against $1 /[\mathrm{s}]$. containing PMA was about 30 - 40\% compared to the intensity from the reaction mixture lacking PMA, indicating that PMA suppressed the spontaneous decomposition of $\mathrm{PGH}_{2}$. The stabilization of $\mathrm{PGH}_{2}$ by $\mathrm{PMA}$ was further confirmed by immunoassay using anti-PGE 2 antibody. ${ }^{17}$ Alkaline phosphatase coupled $\mathrm{PGE}_{2}\left(\mathrm{PGE}_{2}-\mathrm{AP}\right)$ effectively bound to the immobilized anti$\mathrm{PGE}_{2}$ antibody (Fig. 2C, bar 1) in the presence of fresh $\mathrm{PGH}_{2}$. On the contrary, the binding of $\mathrm{PGE}_{2}$-AP to the immobilized anti-PGE $\mathrm{PG}_{2}$ antibody was effectively prevented in the presence of $\mathrm{PGE}_{2}$ (Fig. 2C, bar 3). The amount of bound $\mathrm{PGE}_{2}-\mathrm{AP}$ was significantly reduced in the presence of $\mathrm{PGH}_{2}$, incubated at room temperature for $10 \mathrm{~min}$ (Fig. $2 \mathrm{C}$, bar 2), indicating that substantial amount of $\mathrm{PGH}_{2}$ was decomposed within 10 min incubation and the decomposed product of $\mathrm{PGH}_{2}$ interfered the binding of $\mathrm{PGE}_{2}-\mathrm{AP}$ to anti-PGE $\mathrm{PG}_{2}$ antibody. However, the binding of $\mathrm{PGE}_{2}-\mathrm{AP}$ to anti-PGE 2 antibody was not interfered by $\mathrm{PGH}_{2}$ when it was incubated with $100 \mu \mathrm{M}$ PMA at room temperature for $10 \mathrm{~min}$ (Fig. 2C, bar 4). These results demonstrate that PMA effectively prevented the spontaneous cleavage of $\mathrm{PGH}_{2}$, and the NADH produced from the reaction mixture containing PMA resulted only from the $\mathrm{PGE}_{2}$-dependent reduction of $\mathrm{NAD}^{+}$rather than the oxidation of $\mathrm{PGF}_{2}$.

The effect of PMA on the stabilization of $\mathrm{PGH}_{2}$ was further examined by measuring the production of NADH from the reaction mixture containing various concentrations of PMA. When the reaction mixture of $\mathrm{PGH}_{2}, 15-\mathrm{PGDH}$ and $\mathrm{NAD}^{+}$were incubated with $10-100 \mu \mathrm{M}$ of PMA for $20 \mathrm{~min}$, the amount of $\mathrm{NADH}$ produced from the spontaneous decomposition of $\mathrm{PGH}_{2}$ was dramatically decreased and reached a basal level at a PMA concentration of $50 \mu \mathrm{M}$ or higher (Fig. 3, O). Whereas, the amount of NADH produced from the reaction mixture of $\mathrm{PGH}_{2}$, mPGES-1, 15-PGDH and $\mathrm{NAD}^{+}$decreased to $40 \%$ at a PMA concentration of $50 \mu \mathrm{M}$ or higher (Fig. $3, \bullet$ ). These results suggest that $50-100 \mu \mathrm{M}$ of PMA was enough to stabilize and suppress spontaneous decomposition of $\mathrm{PGH}_{2}$. Although the protection of $\mathrm{PGH}_{2}$ by PMA is not clearly understood, PMA may interact with the alkylperoxide group of $\mathrm{PGH}_{2}$ and prevent further oxidation by oxygen species. Considering the amount of NADH 


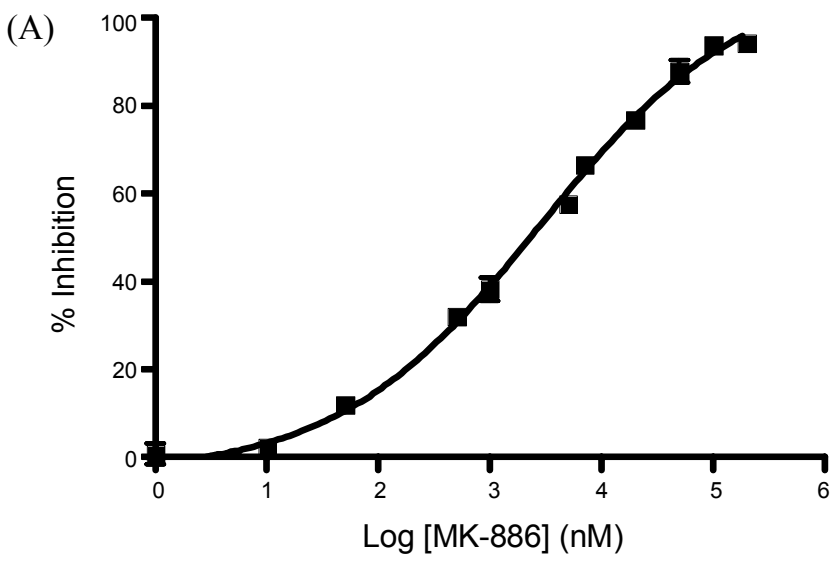

(B)

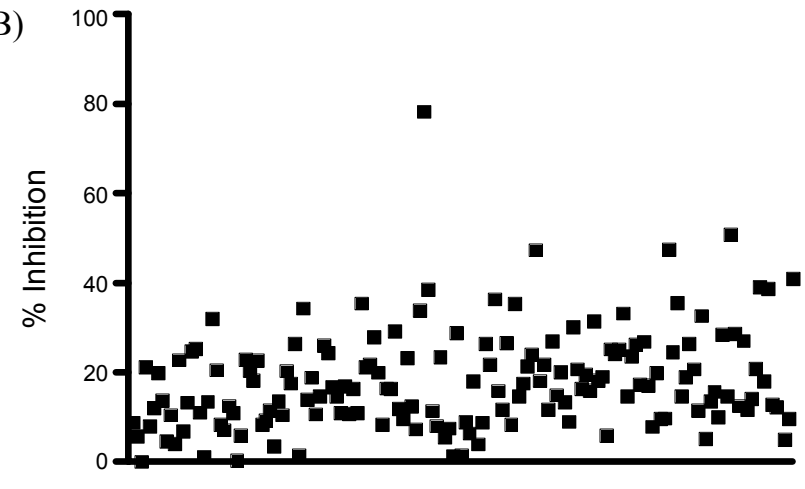

Compounds

Figure 5. Validation of the coupled enzyme assay method for highthroughput screening. (A) Concentration dependent-inhibitory activity of MK- 886 was measured after incubation of different concentrations of MK-886 with the two enzymes for $20 \mathrm{~min}$, and then the amount of NADH produced was measured after $20 \mathrm{~min}$ incubation at room temperature. (B) The inhibitory activities of 160 -selected compounds measured by the coupled enzyme assay method as described above.

produced from the reaction mixture containing only 15-PGDH as negative control (Fig. 2B and C, $\mathbf{m}$ ), the amount of NADH produced from the reaction mixture containing PMA (Fig. 2B, $\mathbf{\Delta}$ ) was similar to the NADH generated from the reaction in the absence of PMA (Fig. 2A, $\mathbf{\Lambda}$ ).

Validation of the couple enzyme assay. To determine if this novel coupled-enzyme assay method yielded kinetic parameters that were consistent with previously reported values of mPGES1 , the reaction rate was measured for $40 \mathrm{~s}$ at different concentrations of $\mathrm{PGH}_{2}$ in the presence of $0.1 \mathrm{mM}$ of PMA, $0.2 \mu \mathrm{M}$ of mPGES- 1 and $1.0 \mu \mathrm{M}$ of 15-PGDH. From the rate of NADH production at different concentration of $\mathrm{PGH}_{2}$, a LineweaverBurk plot was obtained (Fig. 4), and the $\mathrm{K}_{\mathrm{m}}$ value of mPGES-1 for $\mathrm{PGH}_{2}$ was determined to be $0.15 \mathrm{mM}$ with $\mathrm{R}$ value of 0.858 , which was in good agreement with the reported values of 0.16 $\mathrm{mM}^{6}$ This result indicates that the conditions used in this coupled-enzyme assay were suitable to accurately assess mPGES-1 activity.

To test whether the enzyme-coupled assay method was applicable for the screening of inhibitors of mPGES-1, the inhibitory activity of previously known inhibitors of mPGES-1 and randomly selected chemical compounds were measured using this assay method. MK-886, an inhibitory compound of mPG$\mathrm{ES}-1$ with an $\mathrm{IC}_{50}$ value of $3.2 \mu \mathrm{M},{ }^{3}$ showed inhibitory activity in the coupled enzyme assay with an $\mathrm{IC}_{50}$ value of $2.8 \mu \mathrm{M}$ (Fig. $5 \mathrm{~A})$. To further test the utility of the coupled-enzyme assay for screening chemical libraries, the inhibitory activities of 160 -selected compounds in 96-well plate were assayed. Fig. 5B showed the inhibitory activities of the screened compounds at a concentration of $20 \mu \mathrm{M}$. The percent inhibition was calculated as follows: $\left[1-\left(\mathrm{F}-\mathrm{F}^{0}\right) /\left(\mathrm{F}^{100}-\mathrm{F}^{0}\right)\right] \times 100(\%)$, where $\mathrm{F}^{100}$ was the fluorescence intensity from the positive control not containing the inhibitory compound, $\mathrm{F}^{0}$ was the fluorescence intensity from the negative control, and $\mathrm{F}$ was the fluorescence intensity from the reaction mixture incubated with a particular compound. To assess the quality of the assay, a Z' factor that reflects both the assay signal dynamic range and data variation ${ }^{30}$ was determined. The Z' factor for the assay was determined to be $0.86 \pm 0.03$, indicating that this was reliable high-throughput screening (HTS) assays.

In summary, we have developed an efficient and stable coupled-enzyme assay that consists of mPGES-1 and 15-PGDH. In particular, the spontaneous decomposition of $\mathrm{PGH}_{2}$ was effectively prevented by PMA, and this stabilizing effect increased the reaction time of the coupled-enzyme assay, which is critical for screening large numbers of chemicals. In addition, the high Z' value clearly indicated that this coupled-enzyme assay system was appropriate for high-throughput screening

Acknowledgments. This work was supported by grants from the 21C Frontier Research Program, Functional Proteomics Research, Ministry of Education, Science and Technology, Korea. We also thank for the support of Kookmin Research Fund.

\section{References}

1. Funk, C. D. Science 2001, 294, 1871-1875.

2. Murakami, M.; Naraba, H.; Tanioka, T.; Semmyo, N.; Natakami, Y.; Kojima, F.; Ikeda, T.; Feuki, M.; Ueno, A.; Oh, S.; Kudo, I. J. Biol. Chem. 2000, 275, 32783-32792.

3. Mancini, J. A.; Blood, K.; Gordon, J. R.; Claveau, D.; Chan, C. C.; Riendeau, D. J. Biol. Chem. 2001, 276, 4469-4475.

4. Stichtenoth, D. O.; Thorén, S.; Bian, H.; Peters-Golden, M.; Jakobsson, P. J.; Crofford, L. J. J. Immunol. 2001, 167, 469-574.

5. Filion, F.; Bouchard, N.; Goff, A. K.; Lussier, J. G.; Sirois, J. J. Biol. Chem. 2001, 276, 34323-34330.

6. Kamei, D.; Murakami, M.; Nakatani, Y.; Ishikawa, Y.; Ishii, T.; Kudo, I. J. Biol. Chem. 2003, 278, 19396-19405.

7. Yoshimatsu, K.; Altorki, N. K.; Golijanin, D.; Zhang, F.; Jakobsson, P. J.; Dannenberg, A. J.; Subbaramaiah, K. Clin. Cancer Res. 2001, 7, 2608-2610.

8. Jakobsson, P. J.; Thorén, S.; Morgenstern, R.; Samuelsson, B. Identification of human prostaglandin E synthase: a microsomal, glutathione-dependent, inducible enzyme, constituting a potential novel drug target, Proc. Natl. Acsd. Aci. U.S.A. 1999, 96, 7220-7225.

9. Catley, M. C.; Chivers, J. E.; Cambridge, L. M.; Holden, N.; Slater, D. M.; Staples, K. J.; Bergmann, M. W.; Loser, P.; Barnes, P. J.; Newton, R. FEBS Lett. 2003, 547, 75-79.

10. Naraba, H.; Murakami, M.; Matsumoto, H.; Shimbara, S.; Ueno, A.; Kudo, I.; Ohishi, S. J. Immunol. 1998, 160, 2974-2982.

11. Fournier, T.; Fadok, V.; Henson, P. M. J. Biol. Chem. 1997, 272, 31065-31072. 
12. Ushikubi, F.; Segi, E.; Sugimoto, Y.; Murata, T.; Matsuoka, T.; Kobayashi, T.; Hizaki, H.; Tuboi, K.; Katsuyama, M.; Ichikawa, A.; Tanaka, T.; Yoshida, N.; Narumiya, S. Nature 1998, 395, 281284.

13. Samad, T. A.; Sapirstein, A.; Woolf, C. J. Trends Mol. Med. 2002, 8, 390-396.

14. Tanioka, T.; Nakatani, Y.; Semmyo, N.; Murakami, M.; Kudo, I. J. Biol. Chem. 2000, 75, 32775-32782.

15. Trebino, C. E.; Stock, J. L.; Gibbons, C. P.; Naiman, B. M.; Wachtmann, T. S.; Umland, J. P.; Pandher, K.; Lapointe, J. M.; Saha, S.; Roach, M. L.; Carter, D.; Thomas, N. A.; Durtschi, B. A.; McNeish, J. D.; Hambor, J. E.; Jakobsson, P. J.; Carty, T. J.; Perez, J. R.; Audoly, L. P. Proc. Natl. Acad. Sci. U.S.A. 2003, 100, 9044-9049.

16. Kudo, I.; Murakami, M. J. Biochem. Mol. Biol. 2005, 38, 633-638.

17. Massé, F.; Guiral, S.; Fortin, L. J.; Cauchon, E.; Ethier, D.; Guay, J. J. Biomol. Screen. 2005, 10, 599-605.

18. Ouellet, M.; Falgueyret, J. P.; Ear, P. H.; Pen, A.; Mancini, J. A.; Riendeau, D. Protein Expr. Purif. 2002, 26, 489-495.

19. Thorén, S.; Weinander, R.; Saha, S.; Jegerschöld, C.; Pettersson, P. L.; Samuelsson, B. J. Biol. Chem. 2003, 278, 22199-22209.
20. Percival, M. D. Anal. Biochem. 2003, 313, 307-310.

21. Smith, W. L. Am. J. Physiol. 1992, 263, F181-F191.

22. Nugteren, D. H.; Christ-Hazelhof, E. Adv. Prostaglandin Thromboxane Res. 1980, 6, 129-137.

23. Salomon, R. G.; Miller, D. B.; Zagorski, M. G.; Coughlin, D. J. J. Am. Chem. Soc. 1983, 106, 6049-6060.

24. Kim, W. I.; Choi, K. A.; Do, H. S. BMB reports 2008, 41, 808-813.

25. Cho, H.; Oliveira, M. A.; Tai, H.-H. Arch. Biochem. Biophy. 2003, 419, 139-146.

26. Smith, P. K.; Krohn, R. I.; Hermanson, G. T.; Mallia, A. K.; Gartner, F. H.; Provenzano, M. E.; Fujimoto, E. K.; Golki, N. M.; Olson, B. J.; Klenk, D. C. Anal. Biochem. 1985, 150, 76-85.

27. Thoren, S.; Weinander, R.; Saha, S.; Jegerschold, C; Pettersson, P. L.; Samuelsson, B.; Hebert, H.; Hamberg, M.; Morgenstern, R.; Jakobsson, P.-J. J. Biol. Chem. 2003, 278, 22199-22209.

28. Cho, H.; Tai, H.-H. Prostglan. Leukot. Essen. Fatty Acids 2002, 66, 505-509.

29. Frenkel, P.; Abma, C. United States Patent 1998, 5717304.

30. Zhang, J. H.; Chung, T. D.; Oldenburg, K. R. J. Biomol. Screen. 1999, 4, 67-73. 